\title{
Colour Removal from Model Solutions by Coagulation - Surface Charge and Floc Characterisation Aspects
}

\section{S. Gaydardzhiev , J. Karthikeyan \& P. Ay}

To cite this article: S. Gaydardzhiev , J. Karthikeyan \& P. Ay (2006) Colour Removal from Model Solutions by Coagulation - Surface Charge and Floc Characterisation Aspects, Environmental Technology, 27:2, 193-199, DOI: 10.1080/09593332708618633

To link to this article: https://doi.org/10.1080/09593332708618633

曲 Published online: 11 May 2010.

Submit your article to this journal $๘$

Џ Article views: 86

Q View related articles $\sqsubset$

7 Citing articles: 8 View citing articles 준 


\title{
COLOUR REMOVAL FROM MODEL SOLUTIONS BY COAGULATION - SURFACE CHARGE AND FLOC CHARACTERISATION ASPECTS
}

\author{
S. GAYDARDZHIEV ${ }^{1 *}$, J. KARTHIKEYAN ${ }^{2}$ AND P. AY ${ }^{1}$
}

${ }^{1}$ Lehrstuhl Aufbereitungstechnik, Brandenburg Technical University, Siemens-Halske-Ring 8, 03046 Cottbus, Germany ${ }^{2}$ College of Engineering, Sri Venkateswara University, 517502 Tirupati, Andhra Pradesh, India

(Received 8 February 2005; Accepted 26 September 2005)

ABSTRACT

\begin{abstract}
Chemical coagulation applied for colour removal from dye bearing solutions has been investigated from the point of view of surface charge progression. Two commercially used dyes, i.e. CI Acid Blue 113 and CI Disperse Blue 26 have been tested, employing three common coagulants: alum, aluminium chloride and ferric chloride. Coagulant type and dose level and $\mathrm{pH}$ of the dye solution have been studied as process parameters affecting surface charge and degree of colour removal after filtration of coagulated dye. It has been found, that both dyes could be almost completely removed with the tested coagulants, when supplied however at different dosages. From one side, the correlation between surface charge and colour removal suggests that destabilization of colour colloids occurs as a result of charge neutralization followed by removal by filtration. From other side, the lack of re-stabilization and continued high colour removal even at increased coagulant dosages implies enmeshment of destabilized dye colloids into the hydroxy flocs/precipitates of metal coagulant by "sweep coagulation". Finally, flocs from selected sludge samples have been examined for particle size and shape by image analysis and their key characteristics summarised.
\end{abstract}

Keywords: Coagulation, floc characterization, colour removal, surface charge

\section{INTRODUCTION}

The occurrence and consequent removal of colour from effluents and associated environmental problems pose a major challenge to dye stuff manufacturers, textile finishing industries, pulp and paper and leather industries, water companies, etc. In spite of several physicochemical, chemical and biological processes being investigated for removal of colour from a variety of effluents, there is no consensus regarding a reliable method(s) which is/are technically feasible and economically attractive. This is especially valid in the case of textile industries which employ a spectrum of fibers, chemicals, dyes and finishing agents and whose wastes are continually changing in chemical composition and colour $[1,2,3]$.

Chemical coagulation is foremost among the methods employed for treatment of dye house effluents, being practiced either as pre-, post- or main process. Treatment with chemicals like alum, ferrous and ferric sulphate, ferric chloride, calcium chloride, copper sulphate, aluminium chloride, sulphuric and hydrochloric acid etc., for the removal of colour from a variety of industrial dye wastes, composite mill wastes and sewage combined wastes has been investigated and summed up in excellent reviews $[2,4]$. The peculiarity with coagulation however is, that while certain application classes of dyes respond favourably to chemical treatment, certain other (notably acid and basic) fail to respond at all. The reasons behind these discrepancies are still unclear $[5,6]$ and therefore it is difficult to outline the mechanism of colour removal by coagulation [5]. A general belief is that particle destabilization followed by aggregation takes place, however specific chemical interactions involving chelation/ complexation, precipitation and salting-out may also occur [7]. On the whole, it may be reckoned that whatever the application niche, coagulation and flocculation are seldom accompanied by process optimisation, being mostly practiced like an art rather than as science. Similar difficulties arise also in trying to formulate a common test protocol linking the molecular structure of dyes with their affinity towards bio-elimination [8]. Other technologies like membrane filtration, electrolysis, ozonation etc., have been found also to be effective on a singular basis imparting a certain degree of colour removal, but the combination of two or more methods appears to be a preferred practice $[9,10]$. 
Whilst, measurement of electrophoretic mobility and surface charge is being used as a tool for monitoring of colloidal systems dispersion/aggregation relevant to coagulation and flocculation and some researchers have even attempted to explore its role in activated sludge flocculation and bio-flocculation control [11], there is little information regarding surface charge measurement during colour removal by chemical coagulation.

The presented results originate from a first phase research with the objective of evaluating the feasibility of surface charge measurement approach using model solutions of one acid and one disperse textile dye, coagulated with three common inorganic coagulants. The aim was to examine the influence of coagulant type and dosage on surface charge of dye colloids and if possible to correlate those with the degree of colour removal.

\section{MATERIALS AND METHODS}

Dyes and Coagulants

Two commercially available dyes namely, CI Acid Blue 113 and CI Disperse Blue 26, produced by Atic Industries, India, were used, and their principal characteristics are summarised in Table 1. Test dye solutions were prepared by dissolving $100 \mathrm{mg}$ dye powder in 11 distilled water. When the disperse dye was tested, a dispersing agent "Vernamol-S" from Atic Industries was supplied at $1 \mathrm{~g} \mathrm{l}^{-1}$ as prescribed by the dye manufacturer. Three metal salts supplied by Merck, Germany have been used as coagulants: ferric chloride anhydrous $-\mathrm{FeCl}_{3}$ (a.g.); aluminium chloride $-\mathrm{AlCl}_{3} \cdot 6 \mathrm{H}_{2} \mathrm{O}$ (a.g.) and alum - $\mathrm{Al}_{2}\left(\mathrm{SO}_{4}\right)_{3} \cdot 18 \mathrm{H}_{2} \mathrm{O}$ (extra pure). Working solutions with a molar concentration of $0.06,0.04$ and 0.015 , were prepared fresh before each test. Hydrochloric acid and sodium hydroxide were used as $\mathrm{pH}$ regulators.

\section{Coagulation and Filtration}

$100 \mathrm{ml}$ of the model dye solution were transferred to a $200 \mathrm{ml}$ beaker and placed on a flat 3-cm six-blade paddle, resembling a jar-test rig. Then, a predetermined quantity of coagulant was added to the dye solution and $\mathrm{pH}$ was quickly adjusted to the desired value by addition of an appropriate (pre-determined) quantity of acid/alkali. The suspension was mixed in a single step by stirring at $200 \mathrm{rpm}$ for two minutes, which was considered sufficient to destabilize the dye colloidal solution. Immediately after, two samples were taken: $10 \mathrm{ml}$ for determination of the surface charge and $5 \mathrm{ml}$ for image analysis. The remaining suspension was further transferred into a funnel fitted with an "Osmonics" nylon filter having $5 \mu \mathrm{m}$ pore openings and filtered by gravity. An aliquot from the filtrate was collected and analysed for residual colour concentration and for surface charge.

\section{Determination of Surface Charge and Colour Concentration}

Surface charge density for the coagulated dye suspensions (unfiltered sludge sample) and the filtrates after filtration was determined by means of a particle charge detector PCD-03-pH from Mütek, Germany, working on a streaming potential principle. The exact magnitude of the charge was estimated by titration with oppositely charged titrant until neutralization of the streaming potential

Table 1. Characteristics of the dyes used.

\begin{tabular}{llll}
\hline $\begin{array}{l}\text { Dye } \\
\mathrm{CI}\end{array}$ & Chromophore & $\mathrm{MW}$ & Structure \\
$\mathrm{g} \mathrm{M}^{-1}$ & & & \\
\hline Disperse Blue 26 & Anthraquinone & 298.16 &
\end{tabular}


to zeroccured. Based on the amount of spent titrant until zero charge, the specific surface charge of suspension expressed in meq $\mathrm{g}^{-1}$, was calculated. Colour concentration was calculated based on extinction factor, using an MPM 3000 photometer from WTW, Germany. The highest extinction factor (EF) for the both dyes was found at $585 \mathrm{~nm}$ and accordingly this wavelength was used for construction of calibration curves. The degree of colour removal was estimated based on the difference between colour concentration in the original dye solution and the one detected in the filtrate.

\section{Image Analysis of Coagulated Dye Flocs}

Image analysis was underaken using a "Leica Q600" system. The mean volume diameter of flocs and their roundness and aspect ratio were recorded. The estimation for "Roundness" is given as the ratio between the squared perimeter and the projected area of the object and could be viewed on a first approximation as the fractal dimension. The compactness of an aggregate structure could be evaluated on that basis, with loose structures having a low fractal dimension and compact structures - a higher one. The aspect ratio is defined as a ratio between length and breadth of the object. A wide mouth pipette was used to transfer the flocs from the beaker after coagulation into the observation glass. Before being examined, the sample was carefully diluted with double distilled water in the ratio 1:10 to ensure that single floc aggregates are examined. For each measurement about
100 objects were accounted by the system. The presented values are an average from ten measurements.

\section{RESULTS AND DISCUSSION}

Since system $\mathrm{pH}$ plays an important role in coagulation processes, initial tests were conducted to find the influence of final $\mathrm{pH}$ of dye solution on colour removal employing a constant coagulant dose of $0.5 \mathrm{mM} \mathrm{l}^{-1}$. The $\mathrm{pH}$ of the dye solutions varied between 4 and 12. The results from these tests are not presented, but they revealed slightly differing trends in colour removal, which could be attributed to the intrinsic differences in the nature of the dye suspensions. The disperse dyes are water insoluble and are fine colloidal dispersions, whereas acid dyes form ionogenic micro colloids or macromolecules. Based on the screening, the following $\mathrm{pH}$ values of the dye solution have been chosen for further investigation: $\mathrm{pH} 11$ for the aluminium based coagulants, and $\mathrm{pH} 4$ and $\mathrm{pH} 11$ for the ferric chloride.

\section{Change in Surface Charge for CI Acid Blue 113}

Figures 1 and 2 present the progressive change in surface charge due to incremental addition of coagulant and the respective colour removal for the case of CI Acid Blue 113. The charge measured at zero coagulant dosage is the charge of the pure dye solution.

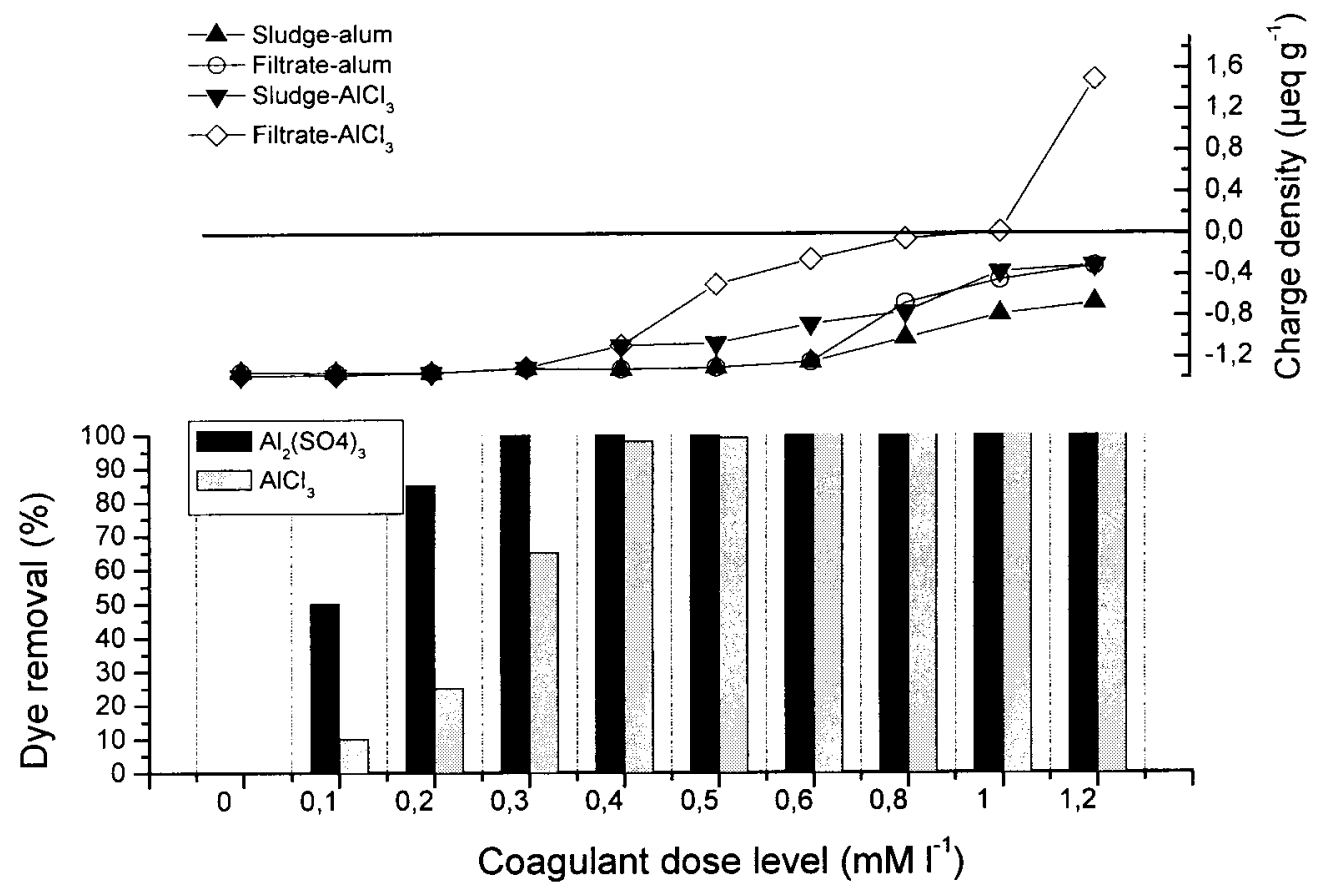

Figure 1. Coagulated dye sludge charge and colour removal using alum and aluminium chloride at pH 11 (the case of CI Acid Blue 113 dye). 


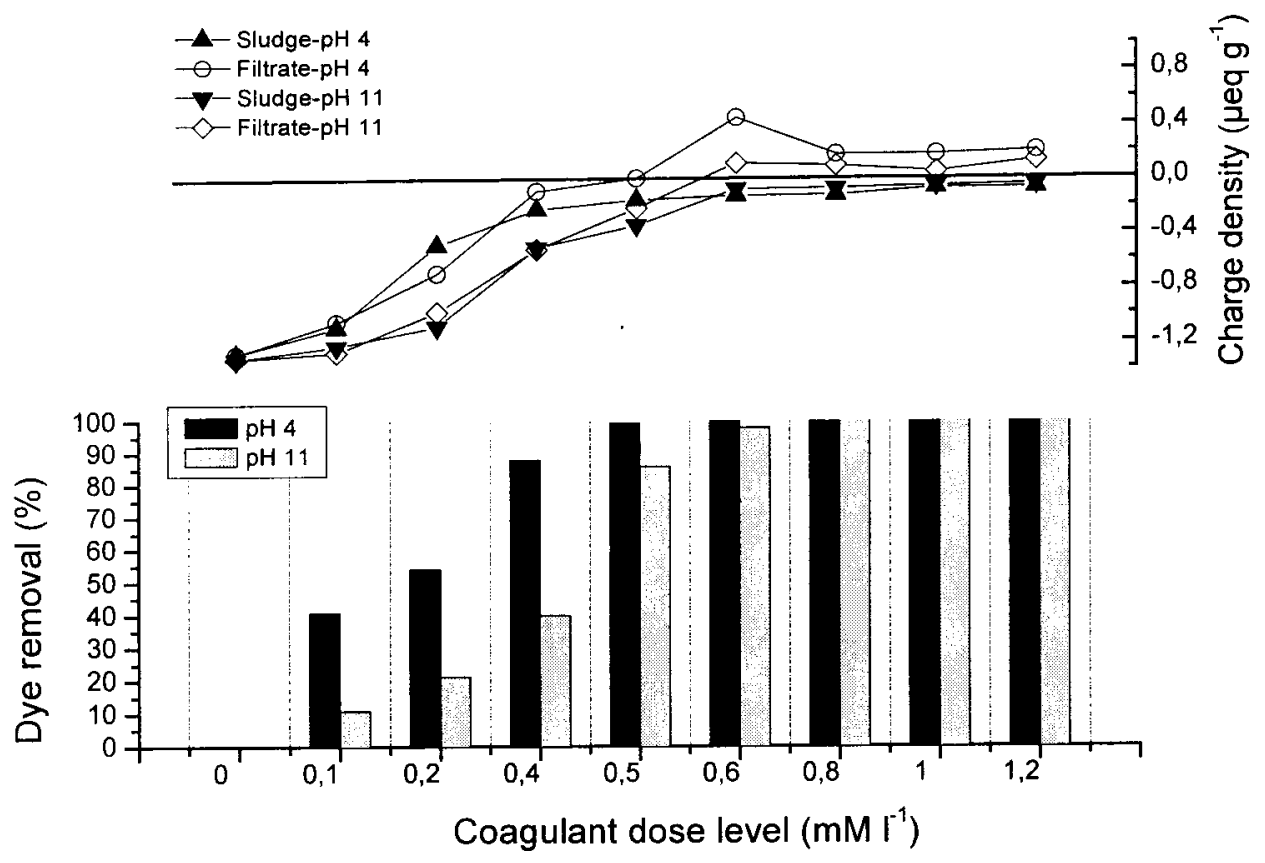

Figure 2. Coagulated dye sludge charge and colour removal using ferric chloride at $\mathrm{pH} 4$ and $\mathrm{pH} 11$ (the case of CI Acid Blue 113 dye).

It can be seen from the figures that the magnitude of surface charge density of the dye colloids gradually decreased as the coagulant dose increased. All three coagulants produced nearly $100 \%$ colour removal but at differing dose levels.

The relationships shown in Figure 1 suggest that as alum dosage was increased, colour removal also increased approaching $100 \%$, however this was not accompanied with a concomitant decrease in the negative surface charge of the suspension. It may therefore be inferred, that alum does not promote predominately charge neutralization mechanism although loss of stability is present. Even at higher dosages of alum, complete charge neutralization has not occurred and there exists a small residual charge, though colour removal was nearly complete. At low dose levels, the surface charge of filtered and unfiltered suspensions was equal and at alum dosages above $0.6 \mathrm{mM} \mathrm{l}^{-1}$ the charge for the filtrate was less negative than that for the sludge. This observation could indicate that the dye colloids might be entrapped/enmeshed into the gelatinous aluminium flocs, which are aggregated products from hydrolization of $\mathrm{Al}^{3+}$ ions, and then removed by what is known as "sweep coagulation".

For the case of aluminium chloride, the progressive increase in coagulant dosage resulted in maximum colour removal accompanied by a slight reduction in surface charge and led to charge reversal in the filtrate at higher than $1 \mathrm{mM} \mathrm{l}^{-}$ ${ }^{1}$ dose levels. The occurrence of a positive charged species in the filtrate after all colour was removed, could be due either to positive species originating from dyestuff fillers/impurities or to emergence of polyvalent cationic coagulant species, like aluminium hydroxide sols [12].

The results shown in Figure 2 indicate that for the dye solution coagulated with ferric chloride at $\mathrm{pH} 11$, the trend in colour removal was similar to the one observed for the aluminium chloride, however higher ferric chloride dosage was required to reach total colour removal. Here, the charge reversal in filtrate occurred at $0.6 \mathrm{mM} \mathrm{l}^{-1}$, where the maximum colour removal was noticed. The charge of coagulated sludge approached zero at coagulant dosages above $0.6 \mathrm{mM} \mathrm{l}^{-1}$. At $\mathrm{pH} 4$, both charge curves were characterised by a more or less similar trend. For both $\mathrm{pH}$ ranges no drop in colour removal was observed at higher coagulant dosages, even after reaching charge reversal in the filtrate.

\section{Change in Surface Charge for CI Disperse Blue 26}

Figures 3 and 4 show that for the disperse dye higher dosages of coagulant are required to attain the same colour removal as that for the acid dye. Again, alum appears to be the best candidate in terms of dose requirement. A more pronounced correlation between charge progression and colour removal could be delineated.

The perusal of the results shown in Figure 3 indicates that at $\mathrm{pH} 11$, both aluminium-based coagulants do not reverse the charge of dye sludge and filtrate to positive. Worthy of note is the good agreement between charge progression and colour removal in the case of aluminium 
chloride.

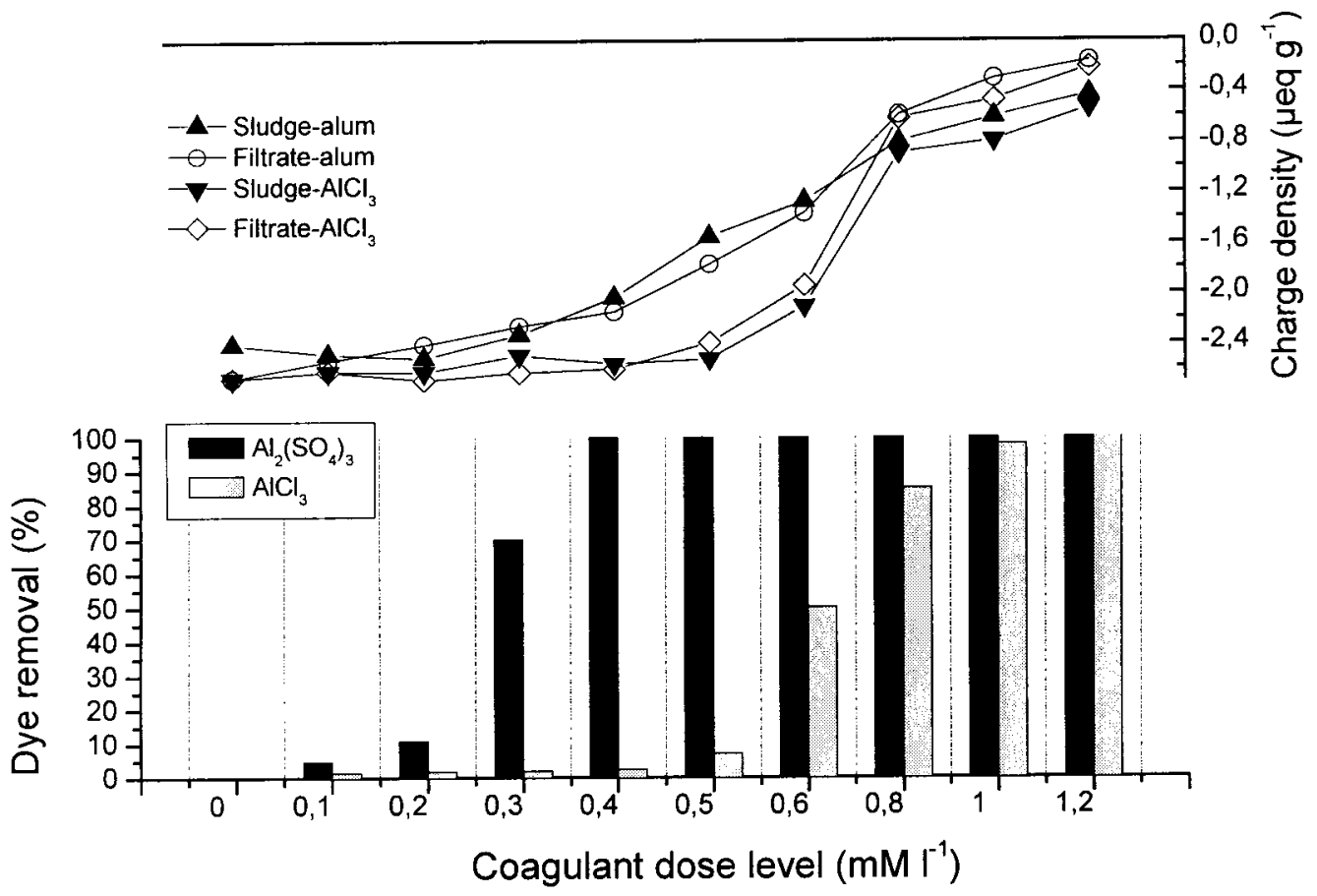

Figure 3. Coagulated dye sludge charge and colour removal using alum and aluminium chloride at $\mathrm{pH} 11$ (the case of $\mathrm{CI}$ Disperse Blue 26 dye).
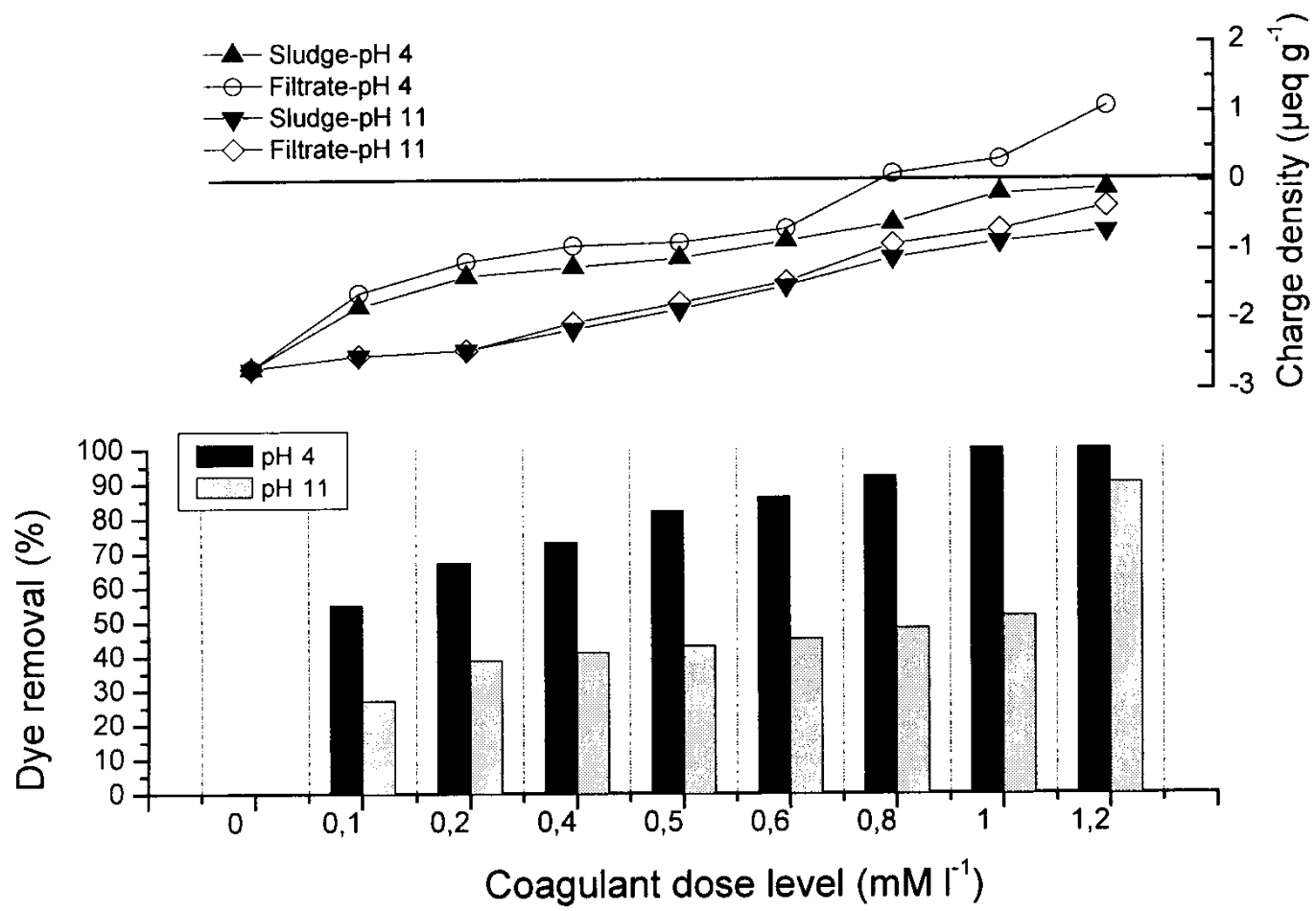

Figure 4. Coagulated dye sludge charge and colour removal using ferric chloride at $\mathrm{pH} 4$ and $\mathrm{pH} 11$ (the case of CI Disperse Blue 26 dye). 
Figure 4 indicates that in contrast to the CI Acid Blue 113 where the role of solution $\mathrm{pH}$ was found to be of minor importance, the $\mathrm{pH}$ effect on coagulation of CI Disperse Blue 26 was more pronounced. The acidic range clearly stimulated more efficient colour removal. At $\mathrm{pH} 4$, nearly double the removal of that achieved at $\mathrm{pH} 11$ was observed for coagulant dose levels from 0.2 to $0.8 \mathrm{mM} \mathrm{l}^{-1}$. Sludge charge has approached zero at dose level of $1 \mathrm{mM} \mathrm{l}^{-1}$ and above, and a close coincidence between point of zero charge and maximum colour removal could be noted. Therefore for the ferric chloride, a charge neutralization mechanism could be attributed at $\mathrm{pH} 4$, while at $\mathrm{pH} 11$ the dye sludge remained negatively charged.

\section{Floc Characterization}

Four samples from coagulation of CI Acid Blue 113 at $\mathrm{pH} 11$ with alum and ferric chloride, each one supplied at two optimal dosages, were examined and their floc characteristics summarized in Table 2. It could be noted that with increasing ferric chloride dosage from 0.5 to $0.6 \mathrm{mM} \mathrm{l}^{-1}$, the mean floc diameter rose slightly from 250 to $280 \mu \mathrm{m}$, while roundness increased from 1.6 to 1.9 , suggesting development of more compact floc structures. This was accompanied by nearly zero charge at $0.6 \mathrm{mM} \mathrm{l}^{-1}$, leading to almost complete colour removal - Fig. 2. However, the alum supplied at half the maximum concentration generated larger and open structured floc aggregates, which are more likely to promote dye colloids removal by sweep coagulation. With a minute increase in alum dosage from 0.2 to $0.3 \mathrm{mM} \mathrm{l}^{-1}$, flocs increased in diameter from 350 to $410 \mu \mathrm{m}$, while roundness dropped from 1.7 to 1.5 . The aspect ratios, giving an idea about elongation of flocs, did not differ significantly. All four samples consisted of aggregates, which owing to their size and shape are unlikely to settle rapidly. The sludge arising from the $\mathrm{FeCl}_{3}$ addition was characterised by the highest amount of fine-sized aggregates. An addition of polymeric flocculant could certainly stimulate development of larger and tear-resistant flocs with improved sedimentation properties and work in this direction is in progress.

\section{CONCLUSIONS}

The results from the presented studies do not permit a conclusion of fundamental validity to be drawn, but are believed to have theoretical implication in revealing some aspects of dye coagulation mechanism. From a practical point of view, they could be of use in the case of implementation of an on-site PCD measurement for coagulants dose rate control, likewise practiced at some municipal wastewater or paper mill treatment plants.

The approach of surface charge density measurement has proved useful, nevertheless further data evaluation should be pursued, involving statistical error analysis as well. The incremental addition of coagulant reduced the negative surface charge of the colloidal dye species and eventually rendered them positive. Except for alum, a good agreement between coagulant dosage and surface charge of the dye colloids was noted. Alum could be recommended as the most promising coagulant on a cost/dosing basis. In the alkaline region, which is mostly the case in dye houses, it promotes predominately sweep coagulation for the both dyes, in contrast to ferric chloride, which stimulates coagulation by charge neutralisation.

Detailed floc characterization studies to complement the presented findings are underway. The results from these studies which involve the use of synthetic primary coagulants as well, are in compilation. However, since image analysis of dye flocs is tedious (in terms of sample preparation) and time consuming, a LALS method was adapted, with the ultimate goal of obtaining information of practical value to sludge down-stream treatment [13].

\section{ACKNOWLEDGMENT}

One of the authors (JK) wishes to acknowledge the German Council for Academic Exchange (DAAD) in providing financial support for a three-month placement at BTU-Cottbus.

Table 2. Floc characteristics of selected coagulated dye samples (CI Acid Blue 113).

\begin{tabular}{lllll}
\hline $\begin{array}{l}\text { Sample } \\
\text { No }\end{array}$ & $\begin{array}{l}\text { Coagulant } \\
\text { (dosage, final pH) }\end{array}$ & $\begin{array}{l}\text { Floc mean } \\
\text { size }(\mu \mathrm{m})\end{array}$ & Roundness & $\begin{array}{l}\text { Aspect } \\
\text { Ratio }\end{array}$ \\
\hline 1 & Alum $\left(0.2 \mathrm{mM} \mathrm{l}^{-1}, \mathrm{pH} \mathrm{11}\right)$ & 350 & 1.7 & 1.6 \\
2 & Alum $\left(0.3 \mathrm{mM} \mathrm{l}^{-1}, \mathrm{pH} \mathrm{11}\right)$ & 400 & 1.5 & 1.7 \\
3 & $\mathrm{FeCl}_{3}\left(0.5 \mathrm{mM} \mathrm{l}^{-1}, \mathrm{pH} \mathrm{11)}\right.$ & 250 & 1.6 & 1.9 \\
4 & $\mathrm{FeCl}_{3}\left(0.6 \mathrm{mM} \mathrm{l}^{-1}, \mathrm{pH} \mathrm{11)}\right.$ & 280 & 1.9 & 1.8 \\
\hline
\end{tabular}

\section{REFERENCES}

1. Vandevivere, P., Bianchi, R., Werstaete, W., Treatment and reuse of waste water from the textile wet-processing industry: 
Review of emerging technologies, J. Chem. Technol. Biotechnol., 72, 289-302 (1998).

2. Hao, O., Kim, H. and Chiang, P., Decolorization of wastewater, Crit. Rev. Environ. Sci. Technol., 30, 449-505 (2000).

3. Robinson, T., McMullan, G., Marchant, R. and Nigam, P., Remediation of dyes in textile effluent: a critical review on current treatment technologies with a proposed alternative, Biores. Technol., 77, 247-255 (2001).

4. Marmagne, O. and Coste, C., Color removal from textile plant effluents, Am. Dyest. Rep., 4, 15-21 (1996).

5. Venkata-Mohan, S., Srimurali, S., Sailaja, P. and Karthikeyan, J., Removal of a monoazo acid dye from aqueous solution by adsorption and chemical coagulation, Environ. Eng. Pollut., 1 149-154 (1999).

6. Venkata-Mohan, S. and Karthikeyan, J., Removal of colour from acid and direct dyes by adsorption onto silica fumes, Fres. Environ. Bull., 7, 51-53 (1998).

7. Karthikeyan, J., Removal of colour from textile dye wastes by chemical coagulation, Ph.D. Thesis, Indian Institute of Technology, Kanpur, India (1990).

8. Greaves, A., Philips, D. and Taylor, J., Correlation between the bioelimination of anionic dyes by an activated sewage sludge with molecular structure, J. Soc. Dyers Col., 115, 363-365 (1999).

9. Hatton, W. and Simpson, A., Color removal from sewage effluents using chemical flocculants, Environ. Technol. Lett., 7 413-424 (1986).

10. Kang, S. and Chang, C., Coagulation of textile secondary effluents with Fenton's reagent, Water Sci. Technol., 36, 115-212 (1997).

11. Liao, B., Allen. D., Dreppo, I., Leprard, G. and Liss, S., Surface properties of sludge and their role in bioflocculation and settleability, Water Res., 35, 339-350 (2001).

12. Licsko, I., Realistic coagulation mechanisms in the use of aluminium and iron (III) salts, Water Sci. Technol., 36, 103-110 (1997).

13. Bushel, G., Yan, Y., Woodfield, D., Raper J. and Amal, R., On the techniques for measurement of the mass fractal dimension of aggregates. Adv. Coll. Interf. Sci., 95, 1-50 (2002). 
